\title{
Computational Investigation of Interaction of Titanocene Dichloride Anti-Cancer Drug with Carbon Nanotube in the Presence of External Electric Field
}

\author{
Reza Ghiasi ${ }^{1}{ }^{*}{ }^{\mathbb{D}}$, Maryam Vasfi Sofiyani ${ }^{1}$, Rashin Emami ${ }^{1, *}$ \\ 1 Department of Chemistry, East Tehran Branch, Islamic Azad University, Tehran, Iran; rezaghiasi1353@yahoo.com \\ (R.G.); maryam.vasfi1375@gmail.com (M.V.S.); rashin.emami@yahoo.com (R.E.); \\ * Correspondence: rezaghiasi1353@yahoo.com;
}

Scopus Author ID 6507495898

Received: 8.12.2020; Revised: 2.01.2021; Accepted: 4.01.2021; Published: 6.01.2021

\begin{abstract}
In this work, the interaction between titanocene dichloride, an anticancer drug, and carbon nanotube was studied at the B3LYP-D3/6-311G(d,p) level of theory. The external electric field effects on the total energy, dipole moment, electronic spatial extent (ESE), and the HOMO-LUMO gap of the $\mathrm{Cp} 2 \mathrm{TiCl} 2 . .$. nanotube molecule were studied. Also, the interaction energy values of the titanocene dichloride with carbon nanotube were calculated. We found good linear relationships between interaction energy, dipole moment, and ESE with external electric field strength.
\end{abstract}

Keywords: titanocene; dichloride, carbon nanotube; interaction energy; electronic spatial extent (ESE); external electric field (EEF).

(C) 2020 by the authors. This article is an open-access article distributed under the terms and conditions of the Creative Commons Attribution (CC BY) license (https://creativecommons.org/licenses/by/4.0/).

\section{Introduction}

After the discovery of the anticancer activity of titanocene dichloride $\left(\mathrm{Cp}_{2} \mathrm{TiCl}_{2}, \mathrm{Cp}=\right.$ $\left.\eta^{5}-\left(\mathrm{C}_{5} \mathrm{H}_{5}\right)_{2}\right)$, numerous experimental researches have been reported on it [1-3]. Whereas the consequences of phase II clinical trials were unsuitable due to the absence of activity against the examined tumors, the described important research on titanium compounds motivated the attention in new titanium compounds with anticancer properties [4-7].

The action mechanism of the $\mathrm{TiCl}_{2} \mathrm{Cp}_{2}$ is unknown; initial studies recommended that it be connected with the purine bases of DNA [8-10]. Theoretical studies have been conducted on the hydrolysis chemistry of anticancer drug titanocene dichloride [11]. Interaction between titanocene dichloride anticancer drug and $\mathrm{Al}_{12} \mathrm{~N}_{12}$ nano-cluster has been reported [12]. In other investigations, the complexation of titanocene dichloride with $\mathrm{C}_{20}$ and $\mathrm{M}^{+} @ \mathrm{C}_{20}\left(\mathrm{M}^{+}=\mathrm{Li}, \mathrm{Na}\right.$, $\mathrm{K}$ ) cages has been studied [13]. Later, more synthetic attempts have been made for boosting the cytotoxicity of titanocene dichloride derivatives [14-16]. A novel process starting from titanium dichloride and fulvenes $[17,18]$ paved the way for directly accessing highly substituted ansa-titanocenes [19-21].

In their efforts for progressing a drug delivery system, the ability of carbon nanotubes (CNT) and nanocages [22-26] has been studied. Moreover, the planar nanostructures have been considered suitable surfaces for holding and carrying the biological molecules [27-30].

External electric fields influence the molecules' structure, electronic properties, and chemical reactivity [31]. Several computational investigations in this field have been reported [32-48]. 
In this work, we have reported a computational investigation of the interaction of titanocene dichloride anticancer drug with a carbon nanotube in the presence of the external electric field. The external electric field effects on the total energy, dipole moment, electronic spatial extent (ESE), and the HOMO-LUMO gap of the $\mathrm{Cp}_{2} \mathrm{TiCl}_{2} \ldots$ nanotube molecule were explored.

\section{Materials and Methods}

\subsection{Computational methods.}

By Gaussian 09 software package, optimization and vibrational analysis were handled [49]. Geometry optimizations were done using the B3LYP-D3 model. B3LYP-D3 model maintains the benefit of the B3LYP method on the one hand. On the other hand, it modifies simulates the weak interactions well utilizing Grimme term D3 [50]. The standard 6-311G(d,p) basis set [51-54] were regarded for elements. For verifying the optimization structures have no imaginary frequency, harmonic vibrational frequencies were computed.

\section{Results and Discussion}

\subsection{Energetic aspect.}

The structure of the $\mathrm{Cp}_{2} \mathrm{TiCl}_{2} \ldots$ nanotube complex and direction corresponding to the external electric field (EEF) are indicated in Figure 1. The selected carbon nanotube (CNT) is a $(6,0)$ zigzag nanotube with the stoichiometry of $\mathrm{C}_{48} \mathrm{H}_{12}$, in which the hydrogen atoms are considered to saturate the atoms of tubular tips to avoid dangling effects [55].

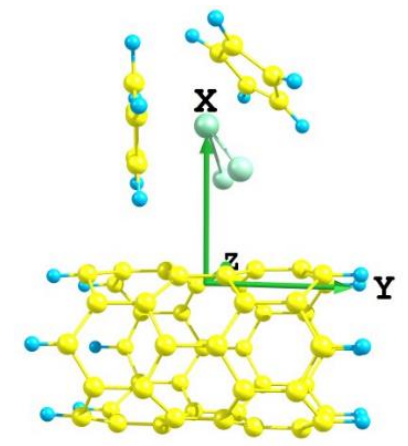

Figure 1. The structure corresponding to $\mathrm{Cp}_{2} \mathrm{TiCl}_{2} \ldots$ nanotube complex and direction corresponding to the used electric field.

Table 1. Strength of external electric field along $+\mathrm{y}$-axis $\left(\mathrm{E}_{\mathrm{y}}, \mathrm{a} . \mathrm{u}\right)$, absolute energy $(\mathrm{E}, \mathrm{a} . \mathrm{u})$, relative energy $(\Delta \mathrm{E}$, $\mathrm{kcal} / \mathrm{mol})$, interaction energy $\left(\Delta \mathrm{E}_{\mathrm{int}}, \mathrm{kcal} / \mathrm{mol}\right)$, dipole moment (Debye), electronic spatial extent (ESE, a.u),

C...Cl distances $(\AA)$ in the $\mathrm{Cp}_{2} \mathrm{TiCl}_{2} \ldots$ nanotube complex at B3LYP-D3/6-311G(d,p) level of theory.

\begin{tabular}{l|l|l|l|l|l|l|l}
$\mathbf{E}_{\mathbf{z}}$ & $\mathbf{E}$ & $\boldsymbol{\Delta} \mathbf{E}$ & $\boldsymbol{\Delta} \mathbf{E}_{\text {int }}$ & $\boldsymbol{\mu}, \mathbf{D e b y e}$ & $\mathbf{E S E}$ & $\mathbf{C} \ldots \mathbf{C l}$ & $\mathbf{C}^{\prime} \ldots \mathbf{C l}$ \\
\hline $\mathbf{0}$ & -3993.6695 & 0.00 & -7.99 & 5.54 & 30619.75 & 3.291 & 3.303 \\
\hline $\mathbf{0 . 0 0 1}$ & -3993.6704 & -0.56 & -7.89 & 6.72 & 30650.85 & 3.303 & 3.318 \\
\hline $\mathbf{0 . 0 0 3}$ & -3993.6761 & -4.13 & -7.66 & 11.97 & 30732.34 & 3.326 & 3.358 \\
\hline $\mathbf{0 . 0 0 5}$ & -3993.6870 & -10.99 & -7.4 & 18.21 & 30844.27 & 3.348 & 3.414 \\
\hline $\mathbf{0 . 0 0 7}$ & -3993.7031 & -21.08 & -7.1 & 24.59 & 31012.85 & 3.497 & 3.374 \\
\hline $\mathbf{0 . 0 0 9}$ & -3993.7242 & -34.32 & -6.62 & 30.70 & 31387.18 & 3.410 & 3.690
\end{tabular}

The energy of $\mathrm{Cp}_{2} \mathrm{TiCl}_{2} \ldots$ nanotube complex is studied at $\mathrm{E}_{\mathrm{y}}=0.000$ to +0.009 a.u. Table 1 shows the energy of $\mathrm{Cp}_{2} \mathrm{TiCl}_{2} \ldots$ nanotube complex at the EEFs in parallel with the $+\mathrm{y}-$ axis. These values show that the application of field along $+y$-axis enhances the complex 
stability. Linear correlation between energy changes in the presence of EEF relative to the absence of $\operatorname{EEF}(\Delta \mathrm{E})$ is:

$$
\Delta E=-3750.5 E_{y}+3.7816 ; R^{2}=0.9320
$$

It can be observed that the $\Delta \mathrm{E}$ values are fitted with the quadratic equation on the strength of EEF:

$$
\Delta E=-404169 E_{y}^{2}-179.41 E_{y}+0.0168 ; R^{2}=1.00
$$

\subsection{Interaction energy.}

Currently, we consider the interaction energy between the $\mathrm{Cp}_{2} \mathrm{TiCl}_{2}$ and nanotube fragment. Calculated interaction energy values are listed in Table 1 . These values show that the interaction energy values of the examined complex are negative.

The interaction energy values corresponding to $\mathrm{Cp}_{2} \mathrm{TiCl}_{2} \ldots$ nanotube complex are collected in Table 1 at the various EEF along +y-axis. It can be seen the weaker interactions by applying stronger fields along $+y$-axis. It can be found a good linear correlation between interaction energy values and the EEF strength:

$$
\Delta E_{\text {int }}=146.85 E_{y}-8.0552 ; R^{2}=0.9769
$$

Weaker interactions are satisfactory for chemical sensors since, in this case, the desorption process will be easy.

Figure 2 indicates the $\mathrm{Cl}$...C distances in the $\mathrm{Cp}_{2} \mathrm{TiCl}_{2}$ and nanotube complex in the absence of EEF. These distances are listed in Table 1 in the presence of EEF. It can be deduced; these distances are longer in the presence EEF than in the absence of EEF. On the other hand, $\mathrm{Cl}$...C distances enhance with increasing of EEF strength along +y-axis. Longer $\mathrm{Cl}$...C distances in the stronger EEF show the weaker interactions between two molecules in this field. This result is compatible with interaction energy values.

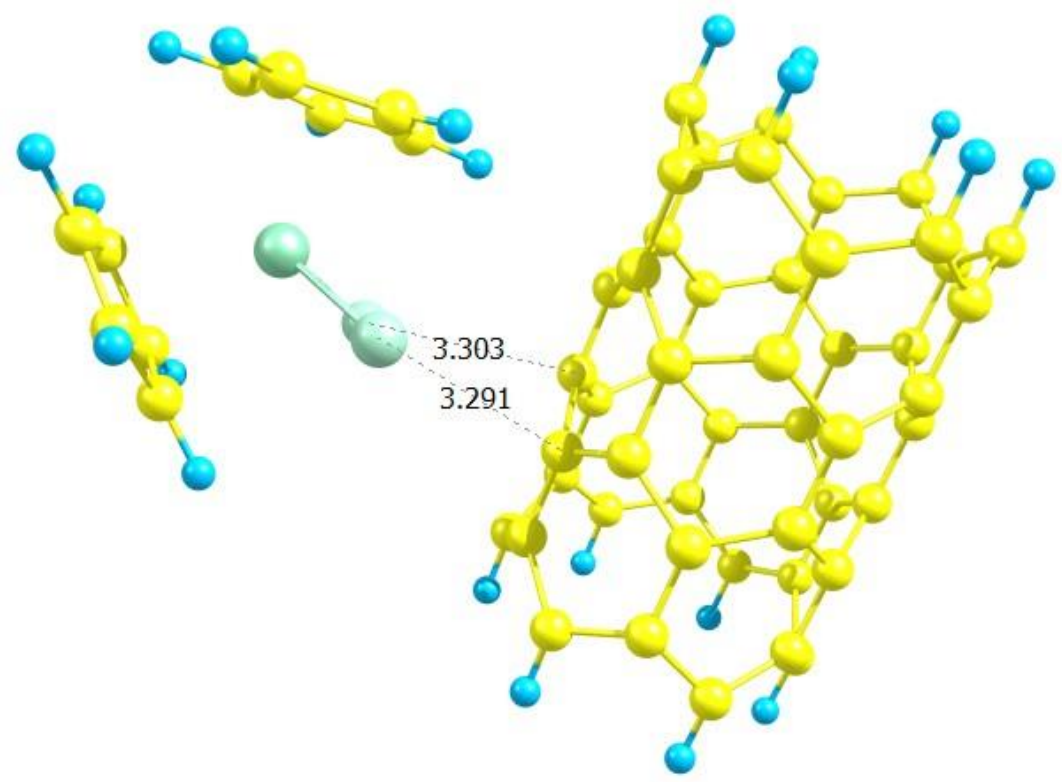

Figure 2. $\mathrm{Cl} \ldots \mathrm{C}$ bond distances in the $\mathrm{Clp}_{2} \mathrm{TiCl}_{2} \ldots$ nanotube complex in the absence of an external electric field.

\subsection{Dipole moment.}

External electric field influences $\mathrm{Cp}_{2} \mathrm{TiCl}_{2} \ldots$ nanotube complex and changes the atomic charge distribution and thus the negative and positive charges centers of the complex. 
Consequently, the complex polarization changes and an induced electric dipole moment are created. Dipole moment values of the $\mathrm{Cp}_{2} \mathrm{TiCl}_{2} \ldots$ nanotube at the various $\mathrm{EEF}$ are collected in Table 1. It can be observed; EEF disturbs the achieved induced electric dipole moment values.

On the other hand, the dipole moment enhances with increasing of the EEF strength. Subsequently, the system polarity changed in the existence of EEF.

There is a good linear dependence of dipole moment values on the strength of electric field:

$$
\mu=2875.1 \mathrm{E}_{\mathrm{y}}+4.3091 ; \quad \mathrm{R}^{2}=0.9937
$$

\subsection{Electronic spatial extent (ESE).}

The surface area covering the volume around any specific molecules is measured as its ESE, which defines its gross receptivity from an external electric field. Table 1 reveals the ESE values for the $\mathrm{Cp}_{2} \mathrm{TiCl}_{2} \ldots$ nanotube complex in different EEFs. It can be observed, ESE values enhance through applying stronger fields along $+\mathrm{y}$-axis.

Linear dependence of the ESE values on the strength of electric field is:

$$
\mathrm{ESE}=78580 \mathrm{E}_{\mathrm{y}}+30547 ; \quad \mathrm{R}^{2}=0.8986
$$

It can be observed that the ESE values are fitted with quadratic equation on the strength of electric field:

$$
\mathrm{ESE}=1 \times 10^{7} \mathrm{E}_{\mathrm{y}}^{2}-9326.6 \mathrm{E}_{\mathrm{y}}+30640 ; \quad \mathrm{R}^{2}=0.9891
$$

\subsection{Molecular orbital analysis.}

Figure 3 shows the plots corresponding to frontier orbitals in the $\mathrm{Cp}_{2} \mathrm{TiCl}_{2} \ldots$ nanotube complex in the field's absence (field value $=0.00$ a.u). It is observed that only the nanotube fragment plays a role in frontier orbitals.

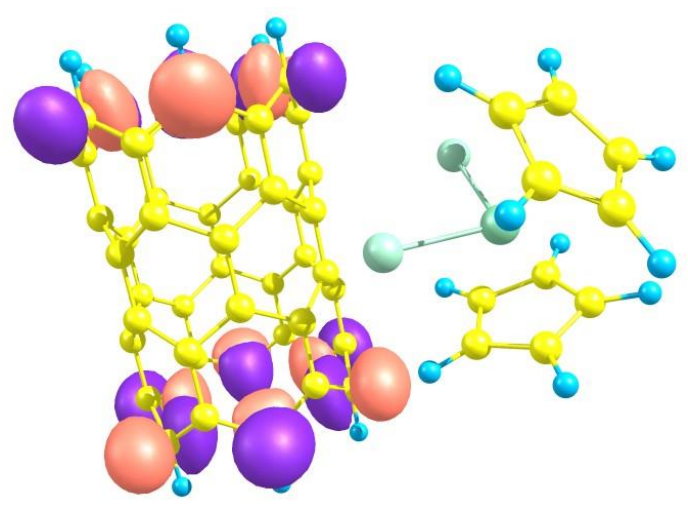

HOMO

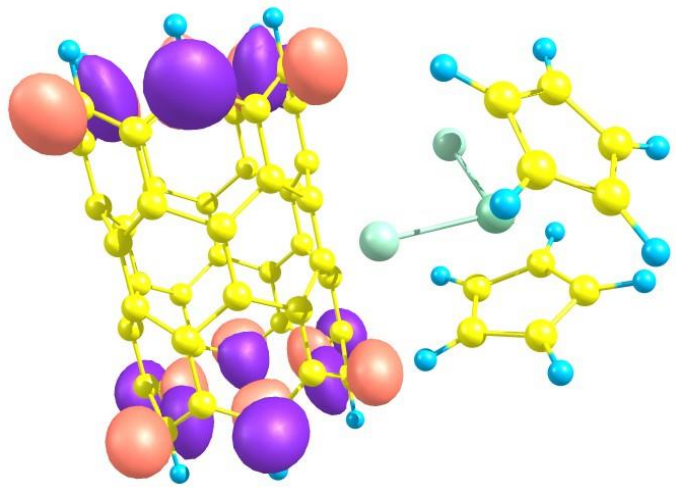

LUMO

Figure 3. HOMO and LUMO plots of the $\mathrm{Cp}_{2} \mathrm{TiCl}_{2}$...nanotube complex in the absence of an external electric field.

Table 2. Frontier orbital energy and HOMO-LUMO gap values of the $\mathrm{Cp}_{2} \mathrm{TiCl}_{2} \ldots$ nanotube complexes along the various external electric field at B3LYP-D3/6-311G(d,p) level of theory.

\begin{tabular}{l|c|c|c}
$\mathbf{E}_{\mathbf{z}}$ & $\mathbf{E}(\mathbf{H O M O})$ & $\mathbf{E}(\mathbf{L U M O})$ & $\mathbf{E}_{\text {Gap }}$ \\
\hline $\mathbf{0}$ & -3.738 & -3.285 & 0.453 \\
\hline $\mathbf{0 . 0 0 1}$ & -3.741 & -3.288 & 0.453 \\
\hline $\mathbf{0 . 0 0 3}$ & -3.749 & -3.293 & 0.456 \\
\hline $\mathbf{0 . 0 0 5}$ & -3.761 & -3.297 & 0.464 \\
\hline $\mathbf{0 . 0 0 7}$ & -3.784 & -3.298 & 0.486 \\
\hline $\mathbf{0 . 0 0 9}$ & -3.830 & -3.284 & 0.546
\end{tabular}


Table 2 shows the values of frontier orbitals energy for $\mathrm{Cp}_{2} \mathrm{TiCl}_{2} \ldots$ nanotube complex in the existence of various external electric fields.

These values show that the values of HOMO energy of $\mathrm{Cp}_{2} \mathrm{TiCl}_{2} \ldots$ nanotube complex decrease in the existence of an electric field along the $+y$-axis. It can be found, the stability of frontier orbitals increases by increasing the electric field strength.

It can be observed that the following linear relationships between the HOMO energy of frontier and strength of the external field:

$$
E(H O M O)=-9.4398 E_{y}-3.7278 ; R^{2}=0.8761
$$

On the other hand, it can be observed that HOMO energy values and strength of the external field are fitted by the quadratic equation:

$$
\mathrm{E}(\mathrm{HOMO})=-1357.1 \mathrm{E}_{\mathrm{y}}^{2}+2.5511 \mathrm{E}_{\mathrm{y}}-3.7404 ; \quad \mathrm{R}^{2}=0.9899
$$

The change in the HOMO-LUMO gap for the $\mathrm{Cp}_{2} \mathrm{TiCl}_{2} \ldots$ nanotube complex is assessed in the existence of external electric fields (Table 2). These values show that the HOMO-LUMO gap increase with enhancing of the external electric field. Consequently, the increase in the energy gap of the HOMO-LUMO decreases electrical conductivity.

Linear dependence of the $E_{G a p}$ values on the strength of electric field is:

$$
\mathrm{E}_{\text {Gap }}=9.1021 \mathrm{E}_{\mathrm{y}}+0.4383 ; \quad \mathrm{R}^{2}=0.7518
$$

It can be observed that the $E_{\text {Gap }}$ values are fitted with quadratic equation on the strength of electric field:

$$
E_{G a p}=1981.7 E_{y}^{2}-8.4072 E_{y}+0.4568 ; \quad R^{2}=0.9758
$$

\subsection{Population of conduction electrons.}

The $\Delta E_{\text {gap }}$ values could be used as an effective variable for the anticancer drug's sensitivity with carbon nanotube. It is related to the population of conduction electrons $(\mathrm{N})$ with the following equation:

$$
N=A \cdot T^{\frac{3}{2}} \cdot \exp \left(-\frac{\Delta E_{g a p}}{2 k_{B} \cdot T}\right)
$$

where $\mathrm{k}_{\mathrm{B}}$ and $\mathrm{A}$ (in electrons $/ \mathrm{m}^{3} \mathrm{~K} 3 / 2$ ) are the Boltzmann's constant and a constant. This equation reveals as $E_{\text {gap }}$ drops; there is an exponential growth in the population of conduction electrons. The electron population will frequently be transformed into an electric signal. The magnitude of this signal could be attributed to the presence of anticancer drugs. A carbon nanotube can identify the presence of $\mathrm{Cp}_{2} \mathrm{TiCl}_{2}$ by making an electrical noise.

\section{Conclusions}

This section is mandatory to be added to the manuscript even if the discussion is unusually long or complex. This section is mandatory to be added to the manuscript even if the discussion is unusually long or complex. This section is mandatory to be added to the manuscript even if the discussion is unusually long or complex. This section is mandatory to be added to the manuscript even if the discussion is unusually long or complex. This section is mandatory to be added to the manuscript even if the discussion is unusually long or complex.

\section{Funding}

This research received no external funding. 


\section{Acknowledgments}

This research has no acknowledgment.

\section{Conflicts of Interest}

The authors declare no conflict of interest.

\section{References}

1. Koepf-Maier, P.; Koepf, H. Non-platinum group metal antitumor agents. History, current status, and perspective. Chem. Rev. 1987, 87, 1137-52, https://doi.org/10.1021/cr00081a012.

2. Köpf-Maier, P.; Köpf, H. Transition and main-group metal cyclopentadienyl complexes: Preclinical studies on a series of antitumor agents of different structural type. Bioinorganic Chemistry. Structure and Bonding 1988, 70, 103-85, https://doi.org/10.1007/3-540-50130-4_3.

3. Clarke, M.J.; Zhu, F.; Frasca, D.R. Non-Platinum Chemotherapeutic Metallopharmaceuticals. Chem. Rev. 1999, 99, 2511-34, https://doi.org/10.1021/cr9804238.

4. Tshuva, E.V.; Peri, D. Modern cytotoxic titanium(IV) complexes; insights on the enigmatic involvement of hydrolysis. Coord. Chem. Rev. 2009, 253, 2098-115, https://doi.org/10.1016/j.ccr.2008.11.015.

5. Gómez-Ruiz, S.; Kaluđerović, G.N.; Polo-Cerón, D.; Prashar, S.; Fajardo, M.; Žižak, Ž.; Juranić, Z.D.; Sabo, T.J. Study of the cytotoxic activity of alkenyl-substituted ansa-titanocene complexes. Inorganic Chemistry Communications 2007, 10, 748-752, https://doi.org/10.1016/j.inoche.2007.03.016.

6. Gómez-Ruiz, S.; Kaluđerović, G.N.; Prashar, S.; Polo-Cerón, D.; Fajardo, M.; Žižak, Ž.; Sabo, T.J.; Juranić, Z.D. Cytotoxic studies of substituted titanocene and ansa-titanocene anticancer drugs. Journal of Inorganic Biochemistry 2008, 102, 1558-1570, https://doi.org/10.1016/j.jinorgbio.2008.02.001.

7. Barroso, S.; Coelho, A.M.; Gómez-Ruiz, S.; Calhorda, M.J.; Žižak, Ž.; Kaluđerović, G.N.; Martins, A.M. Synthesis, cytotoxic and hydrolytic studies of titanium complexes anchored by a tripodal diamine bis(phenolate) ligand. Dalton Transactions 2014, 43, 17422-17433, https://doi.org/10.1039/C4DT00975D.

8. McLaughlin, M.L.; Cronan, J.M.; Schaller, T.R.; Snelling, R.D. DNA-metal binding by antitumor-active metallocene dichlorides from inductively coupled plasma spectroscopy analysis: titanocene dichloride forms DNA- $\mathrm{Cp}_{2} \mathrm{Ti}$ or DNA-CpTi adducts depending on pH. J. Am. Chem. Soc. 1990, 112, 8949-52, https://doi.org/10.1021/ja00180a046.

9. Harding, M.M.; Harden, G.J.; Field, L.D. A 31P NMR study of the interaction of the antitumor active metallocene $\mathrm{Cp} 2 \mathrm{MoCl} 2$ with calf thymus DNA. FEBS Lett. 1993, 322, 291-94, https://doi.org/10.1016/0014-5793(93)81588-q.

10. Murray, J.H.; Harding, M.M. Organometallic Anticancer Agents: The Effect of the Central Metal and Halide Ligands on the Interaction of Metallocene Dihalides Cp2MX2 with Nucleic Acid Constituents. J. Med. Chem. 1994, 37, https://doi.org/10.1021/jm00039a005.

11. Chen, X.; Zhou, L. The hydrolysis chemistry of anticancer drug titanocene dichloride: An insight from theoretical study/ Journal of Molecular Structure: Theochem 2010, 940, 45-49, https://doi.org/10.1016/j.theochem.2009.10.007.

12. Shabani, M.; Ghiasi, R.; Zarea, K.; Fazaeli, R. Quantum chemical study of interaction between titanocene dichloride anticancer drug and $\mathrm{Al}_{12} \mathrm{~N}_{12}$ nano-cluster. Russian Journal of Inorganic Chemistry 2020, 65, 1726-34, https://doi.org/10.1134/S0036023620110169.

13. Ghiasi, R.; Rahimi, M.; Ahmadi, R. Quantum-chemical investigation into the complexation of titanocene dichloride with $\mathrm{C}_{20}$ and $\mathrm{M}^{+} @ \mathrm{C} 20\left(\mathrm{M}^{+}=\mathrm{Li}, \mathrm{Na}, \mathrm{K}\right)$ cages. Journal of Structural chemistry 2021, 61, 1777 86, https://doi.org/10.26902/JSC_id63214.

14. Allen, O.R.; Croll, L.; Gott, A.L.; Knox, R.J.; McGowan, P.C. Functionalized Cyclopentadienyl Titanium Organometallic Compounds as New Antitumor Drugs. Organometals 2004, 23, 288-92, https://doi.org/10.1021/om030403i.

15. Boyles, J.R.; Baird, M.C.; Campling, B.G.; Jain, N. Enhanced anticancer activities of some derivatives of titanocene dichloride. J. Inorg. Biochem. 2011, 84, 159-62, https://doi.org/10.1016/S0162-0134(00)002038.

16. Causey, P.W.; Baird, M.C. Synthesis, Characterization, and Assessment of Cytotoxic Properties of a Series of Titanocene Dichloride Derivatives. Organometals 2004, 23, 4486-4494, https://doi.org/10.1021/om049679w.

17. Teuber, R.; Köppe, R.; Linti, G.; Tacke, M. The X-ray structure of Fe(fulvene)2: The missing link in the direct synthesis of ansa- and Cpi-metallocenes $(\mathrm{Cpi}=\mathrm{C} 5 \mathrm{H} 4 \mathrm{CHMe} 2)$. Journal of Organometallic Chemistry 1997, 545-546, 105-110, https://doi.org/10.1016/S0022-328X(97)00267-2.

18. Fox, S.; Dunne, J.P.; Dronskowski, D.; Schmitz, D.; Tacke, M. Synthesis and Structural Characterisation of a Novel Chiral ansa-Cobaltocenium Hexafluorophosphate. Eur. J. Inorg. Chem. 2002, 3039-46, https://doi.org/10.1002/1099-0682(200211)2002:11<3039::AID-EJIC3039>3.0.CO;2-0. 
19. Rehmann, F.-J.K.; Cuffe, L.P.; Mendoza, O.; Rai, D.K.; Sweeney, N.; Strohfeldt, K.; Gallagher, W.M.; Tacke, M. Heteroaryl substituted ansa-titanocene anticancer drugs derived from fulvenes and titanium dichloride. Appl. Organomet. Chem. 2005, 19, 293-300, https://doi.org/10.1002/aoc.864.

20. Kane, K.M.; Shapiro, P.J.; A, V.; Cubbon, R.; Rheingold, A.L. Reductive Coupling of Fulvenes with Calcium for C2-Symmetric ansa-Metallocenes: Syntheses and Molecular Structures of trans- $\mathrm{Ph} 2 \mathrm{C} 2 \mathrm{H} 2(\eta 5-$

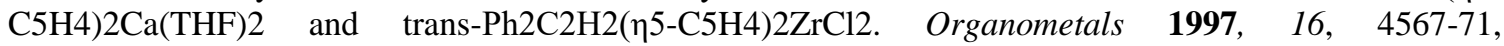
https://doi.org/10.1021/om9704399.

21. Tacke, M.; Allen, L.T.; Cuffe, L.; Gallagher, W.M.; Lou, Y.; Mendoza, O.; M€uller-Bunz, H.; Rehmann, F.-J.K.; Sweeney, N. Novel titanocene anticancer drugs derived from fulvenes and titanium dichloride. J. Organomet. Chem 2004, 689, 2242-49, https://doi.org/10.1016/j.jorganchem.2004.04.015.

22. Ghanbari, H.; Cousins, B.G.; Seifalian, A.M. A nanocage for nanomedicine: Polyhedral oligomeric silsesquioxane (POSS). Macromol Rapid Commun. 2011, 32, 1032-46, https://doi.org/10.1002/marc.201100126.

23. S. Deng, Li, L.; Rees, P. Graphene/MoXY Heterostructures Adjusted by Interlayer Distance, External Electric Field, and Strain for Tunable Devices. ACS Applied Nano Materials 2019, 2, 3977-88, https://doi.org/10.1021/acsanm.9b00871.

24. Mu, X.; Zong, H.; Zhu, L.; Sun, M. External Electric Field-Dependent Photoinduced Charge Transfer in a Donor-Acceptor System in Two-Photon Absorption. The Journal of Physical Chemistry C 2020, 124, 231932, https://doi.org/10.1021/acs.jpcc.9b10086.

25. Li, H.; Yu, X.; Shen, X.; Tang, G.; Han, K. External Electric Field Induced Second-Order Nonlinear Optical Effects in Hexagonal Graphene Quantum Dots. The Journal of Physical Chemistry C 2019, 123, 20020-25, https://doi.org/10.1021/acs.jpcc.9b04907.

26. Fang, L.; Cao, Z. Isoelectronic Doping and External Electric Field Regulate the Gas-Separation Performance of Graphdiyne. The Journal of Physical Chemistry C 2020, 124, 2712-20, https://doi.org/10.1021/acs.jpcc.9b11062.

27. Yaraghi, A.M.; Ozkendir, O.; Mirzaei, M. DFT studies of 5-fluorouracil tautomers on a silicon graphene nanosheet. Superlattices and Microstructures 2015, 85, 784-88, https://doi.org/10.1016/j.spmi.2015.05.053.

28. Bazile, D.V. Nanotechnologies in Drug Delivery - An Industrial Perspective. J. Drug Deliv. Sci. Technol. 2014, 24, 12-21, https://doi.org/10.1016/S1773-2247(14)50002-0.

29. Goenka, S.; Sant, V.; Sant, S. Graphene-based nanomaterials for drug delivery and tissue engineering. J. Control. Release 2014, 173, 75-88, https://doi.org/10.1016/j.jconrel.2013.10.017.

30. Hao, L.; Wang, J.; Zhai, D.; Ma, P.; Ma, C.; Pan, Y.; Jiang, J. Theoretical Study on CL-20-Based Cocrystal Energetic Compounds in an External Electric Field. ACS Omega 2020, 5, 14767-75, https://doi.org/10.1021/acsomega.0c01643.

31. Gao, F.-W.; Xu, H.-L.; Su, Z.-M. Tuning Second-Order Nonlinear Optical Properties of Cross-Linked Carbon Nanotube via External Electric Field. J. Phys. Chem. C 2020, 124, 3778-83, https://doi.org/10.1021/acs.jpcc.9b10759.

32. Neog, B.; Sarmah, N.; Kar, R.; Bhattacharyya, P.K. Effect of external electric field on aziridinium ion intermediate: A DFT study. Computational and Theoretical Chemistry 2011, 976, 60-67, https://doi.org/10.1016/j.comptc.2011.08.002.

33. Bhattacharyya, P.K. Effect of external electric field on ground and singlet excited states of phenylalanine: A theoretical study. Computational and Theoretical Chemistry 2015, 1057, 43-53, https://doi.org/10.1016/j.comptc.2015.01.017.

34. Zahedi, E.; Mozaffari, M.; Karimi, F.-S.; Nouri, A. Density functional theory study of electric field effects on the isomerization of a photochromic molecular switch based on 1,2-dithienylethene. Can. J. Chem. 2014, 92, 317-23, https://doi.org/10.1139/cjc-2013-0589.

35. Kramer, K.H.; Bernstein, R.B. Sudden approximation Applied to rotational excitation of molecules by atoms I. Low angle scattering. J. Chem. Phys. 1964, 40, 200-03, https://doi.org/10.1063/1.1724862.

36. Parthasarathi, R.; Subramanian, V.; Chattaraj, P.K. Effect of electric field on the global and local reactivity indices. Chem. Phys. Lett. 2003, 382, 48-56, https://doi.org/10.1016/j.cplett.2003.09.160.

37. Cerón-Carrasco, J.P.; Jacquemin, D. Electric-field induced mutation of DNA: a theoretical investigation of the GC base pair. Phys. Chem. Chem. Phys. 2013, 15, 4548-53, https://doi.org/10.1039/C2CP44066K.

38. Jissy, A.K.; Datta, A. Designing molecular switches based on DNA-base mispairing, J. Phys. Chem. B 2010, 114, 15311-18, https://doi.org/10.1021/jp106732u.

39. Daneshdoost, V., Ghiasi, R.,Marjani, A., Investigating the Effects of External Electric Field on the Osmabenzyne in the Ground State $\left(\mathrm{S}_{0}\right)$ and First Excited Singlet $\left(\mathrm{S}_{1}\right)$ State: Insight from Structures, Energetics and Properties J. Struc. Chem. 2021, 61:1691. doi 10.1134/S0022476620110037.

40. Shamami, M.K.; Ghiasi, R. The analysis of $\mathrm{Os}^{\circ} \mathrm{C}$ bond and electric field influence on the properties in the Osmium Carbyne Complex, OsCl3 $\left({ }^{\circ} \mathrm{CCH}_{2} \mathrm{CMe}_{3}\right)\left(\mathrm{PH}_{3}\right)_{2}$ : A theoretical insight. J. Chinese. Chem. Soc. 2017, 64, 651-57, https://doi.org/10.1002/jccs.201700020.

41. Ghobadi, H.; Ghiasi, R.; Jamehbozorgi, S. The influence of external electric field on the electronic structure and aromaticity of Iridabenzene: a DFT study. Journal of Structural Chemistry 2019, 60, 547-55.. 
42. Zandiyeh, Z.; Ghiasi, R. A Theoretical approach towards identification of external electric field effect on $\left(\mathrm{h}^{5}-\mathrm{C}_{5} \mathrm{H}_{5}\right) \mathrm{Me}_{2} \mathrm{Ta}\left(\mathrm{h}^{2}-\mathrm{C}_{6} \mathrm{H}_{4}\right)$. Russian Journal of Physical Chemistry A 2019, 93, 482-87, https://doi.org/10.1134/S0036024419030294.

43. Norouzi, P.; Ghiasi, R.; Fazaeli, R.; Effects of External Electric Field on the Hydrolysis of Cisplatin: A Density Functional Theory Approach. Russian Journal of Inorganic Chemistry 2020, 65, 2053-61.

44. Norouzi, P.; Ghiasi, R. Theoretical Understanding the Effects of External Electric Field on the Hydrolysis of anticancer drug titanocene dichloride. Molecular Physics 2020, 118, https://doi.org/10.1080/00268976.2020.1781272.

45. Kazemi, Z.; Ghiasi, R.; Jamehbozorgi, S. The interaction of 5-fluorouracil with graphene in presence of external electric field: A theoretical investigation. Adsorption 2020, 26, 905-11, https://doi.org/10.1007/s10450-019-00140-3.

46. Daneshdoosta, V.; Ghiasi, R.; Marjania, A. Analysis of Bonding Properties of Osmabenzyne in the Ground State $\left(\mathrm{S}_{0}\right)$ and Excited Singlet $\left(\mathrm{S}_{1}\right)$ State: A Quantum-Chemical Calculation. Russian Journal of Physical Chemistry A 2020, 94, 2584-90, https://doi.org/10.1134/S0036024420120080.

47. Ghiasi, R.; Sadeghi, N. Effect of external electric field on the electronic structure and aromaticity of $\mathrm{Cr}(\mathrm{CO})_{3}\left(\mathrm{~h}^{6}-\mathrm{C}_{6} \mathrm{H}_{6}\right) \quad$ complex. Russian Journal of Inorganic Chemistry 2019, 64, 1035-40, https://doi.org/10.1134/S0036023619080114.

48. Yeh, C.-H.; Pham, T.M.L.; Nachimuthu, S.; Jiang, J.-C. Effect of External Electric Field on Methane Conversion on IrO2(110) Surface: A Density Functional Theory Study. ACS Catalysis 2019, 9, 8230-8242, https://doi.org/10.1021/acscatal.9b01910.

49. Frisch, M.J.; Trucks, G.W.; Schlegel, H.B.; Scuseria, G.E.; Robb, M.A.; Cheeseman, J.R.; Scalman, G.; Barone, V.; Mennucci, B.; Petersson, G.A.; Nakatsuji, H.; Caricato, M.; Li, X.; Hratchian, H.P.; Izmaylov, A.F.; Bloino, J.; Zheng, G.; Sonnenberg, J.L.; Hada, M.; Ehara, M.; Toyota, K.; Fukuda, R.; Hasegawa, J.; Ishida, M.; T.Nakajima, Honda, Y.; Kitao, O.; Nakai, H.; Vreven, T.; Montgomery, J.A.; Jr.; Peralta, J.E.; Ogliaro, F.; Bearpark, M.; Heyd, J.J.; Brothers, E.; Kudin, K.N.; Staroverov, V.N.; Kobayashi, R.; J.Normand, Raghavachari, K.; Rendell, A.; Burant, J.C.; Iyengar, S.S.; J.Tomasi, Cossi, M.; Rega, N.; Millam, J.M.; Klene, M.; Knox, J.E.; Cross, J.B.; Bakken, V.; Adamo, C.; Jaramillo, J.; Gomperts, R.; Stratmann, R.E.; Yazyev, O.; Austin, A.J.; Cammi, R.; Pomelli, C.; Ochterski, J.W.; Martin, R.L.; Morokuma, K.; Zakrzewski, V.G.; Voth, G.A.; Salvador, P.; Dannenberg, J.J.; Dapprich, S.; Daniels, A.D.; Farkas, O.; Foresman, J.B.; Ortiz, J.V.; Cioslowski, J.; Fox, D.J. Gaussian 09. Revision A.02, Gaussian, Inc.: Wallingford CT, 2009.

50. Grimme, S. Accurate description of van der Waals complexes by density functional theory including empirical corrections. J. Comput. Chem 2004, 25, 1463-73, https://doi.org/10.1002/jcc.20078.

51. Hay, P.J. Gaussian basis sets for molecular calculations - representation of 3D orbitals in transition-metal atoms. J. Chem. Phys. 1977, 66, 4377-84, https://doi.org/10.1063/1.433731.

52. Krishnan, R.; Binkley, J. S.; Seeger, R.; Pople, J.A. Self consistent molecular orbital methods. XX. A basis set for correlated wave functions. J. Chem. Phys. 1980, 72, 650-54, https://doi.org/10.1063/1.438955.

53. McLean, A.D.; Chandler, G.S. Contracted Gaussian-basis sets for molecular calculations. 1. 2nd row atoms, $\mathrm{Z}=11-18$. J. Chem. Phys. 1980, 72, 5639-48, https://doi.org/10.1063/1.438980.

54. Wachters, A.J.H. Gaussian basis set for molecular wavefunctions containing third-row atoms, J. Chem. Phys. 1970, 52, 1033-36, https://doi.org/10.1063/1.1673095.

55. Bagheri, Z.; Mirzaei, M.; Hadipour, N.L.; Abolhassani, M.R. Density functional theory study of boron nitride nanotubes: calculations of the N-14 and B-11 nuclear quadrupole resonance parameters. J. Comput. Theor. Nanosci. 2008, 5, 614-18, https://doi.org/10.1166/jctn.2008.026. 